\title{
Endoscopic endonasal surgery for anterior skull base meningiomas
}

\author{
Michael B. Avery ${ }^{1,2}$, Garni Barkhoudarian ${ }^{1,2}$, Daniel F. Kelly ${ }^{1,2}$ \\ ${ }^{1}$ Pacific Neuroscience Institute, Santa Monica, CA 90404, USA. \\ ${ }^{2}$ Saint John's Cancer Institute, Providence Saint John's Health Center, Santa Monica, CA 90404, USA. \\ Correspondence to: Dr. Daniel F. Kelly, Pacific Neuroscience Institute, 2125 Arizona Avenue, Santa Monica, CA 90404, USA. \\ E-mail:dkelly@pacificneuro.org
}

How to cite this article: Avery MB, Barkhoudarian G, Kelly DF. Endoscopic endonasal surgery for anterior skull base meningiomas. Mini-invasive Surg 2021;5:17. https://dx.doi.org/10.20517/2574-1225.2021.05

Received: 14 Jan 2021 First Decision: 19 Feb 2021 Revised: 6 Apr 2021 Accepted: 8 Apr 2021 Available online: 17 Apr 2021

Academic Editors: Giulio Belli, Oreste de Divitiis Copy Editor: Xi-Jun Chen Production Editor: Xi-Jun Chen

\begin{abstract}
Meningiomas of the tuberculum sellae, planum sphenoidale and olfactory groove region are relatively common. Traditionally these meningiomas have been approached through several transcranial approaches. More recently, keyhole approaches have been utilized with success even for large tumors. Endoscopic approaches are an extension of this philosophy, which, in carefully selected patients, may be an excellent alternative, offering a direct line of site from an endonasal approach without brain retraction. Furthermore, bilateral optic canal decompression can be safely and effectively accomplished. We propose that a majority of tuberculum sellae and posterior planum meningiomas may be removed via an endonasal approach, particularly those that are $3 \mathrm{~cm}$ or smaller in maximal diameter with minimal lateral extension beyond the supraclinoid carotid arteries and with medial optic canal invasion. A deepened sella is also a favorable factor for endonasal removal. In contrast, we propose that a minority of olfactory groove meningiomas are ideal candidates for endoscopic trans-cribriform removal given the higher risk of anosmia and cerebrospinal fluid leak via the nasal corridor. Instead, a majority of these tumors can be safely and effectively removed via a transcranial keyhole approach, such as the supraorbital "eyebrow" craniotomy or traditional pterional craniotomy with a higher rate of olfaction preservation.
\end{abstract}

Keywords: Meningioma, endoscopy, anterior skull base, tuberculum sellae, planum sphenoidale, olfactory groove, optic canal decompression

\section{INTRODUCTION}

The era of endoscopic transsphenoidal surgery began in the late 1990s, bringing with it improvement of 
illumination, image quality, viewing angle and dexterity over previous microscopic approaches. Since then, endonasal techniques have expanded into both sagittal and coronal planes, including the anterior skull base $^{[1-8]}$. This region endoscopically is defined posteriorly by the tuberculum sellae, anteriorly by the posterior table of the frontal sinus, and laterally by the junction of the lamina papyracea and the fovea ethmoidalis. The major divisions from anterior to posterior are the cribriform plate, planum sphenoidale and tuberculum sellae, all of which are accessible with the use of straight or angled endoscopes.

Anterior skull base meningiomas are relatively common, with tuberculum sellae/planum sphenoidale representing approximately $5 \%-10 \%$ of all meningiomas, and olfactory groove $8 \%-13 \%{ }^{[6]}$. Tuberculum sellae/planum sphenoidal meningiomas frequently exhibit growth patterns that displace the optic nerves and chiasm posteriorly and/or superiorly. Optic canal invasion is present in approximately two thirds of cases $^{[9]}$. This growth pattern results in relatively early detection with small size. Olfactory groove meningiomas, on the other hand, generally are much larger when at presentation due to initial lack of critical mass effect on orbitofrontal cortex.

Traditionally, frontal fossa meningiomas have been approached through several transcranial approaches, including frontal, bifrontal and pterional craniotomies. More recently, keyhole approaches, such as the supraorbital craniotomy, have been utilized with success even for very large tumors ${ }^{[1,11]}$. Endoscopic approaches are an extension of this minimally invasive keyhole philosophy and, in carefully selected patients, they may be an excellent alternative due to the midline location of these tumors, offering a direct line of site from an endonasal approach without brain retraction ${ }^{[5,6,8,12-14]}$. Furthermore, bilateral optic canal decompression can be safely and effectively accomplished in patients with compressive optic neuropathy from tumor extension into the medial optic canals ${ }^{[15-17]}$.

Here we describe both the transplanum/transtuberculum and transcribriform approaches for anterior skull base meningiomas, including the indications, limitations and outcomes. We propose that a majority of tuberculum sellae and posterior planum meningiomas can be removed with an endonasal approach given the superior access to the medial optic canals. In contrast, only a minority of olfactory groove meningiomas are ideal for the endonasal route given that the transcribriform approach will inevitably lead to anosmia in the vast majority of patients. In fact, recent systematic reviews by Shetty et al ${ }^{[18]}$ and Yang et al. ${ }^{[19]}$ of studies comparing transcranial and endoscopic approaches for tuberculum sellae/planum sphenoidale and olfactory groove meningiomas, respectively, found that $39 \%$ of the former are performed endoscopically $v$ s. only $19 \%$ for the latter. We also emphasize that the supraorbital "eyebrow" craniotomy is an excellent and complimentary alternative for anterior skull base meningiomas ${ }^{[10]}$.

\section{TRANSPLANUM/TRANSTUBERCULUM APPROACH FOR TUBERCULUM \& POSTERIOR PLANUM MENINGIOMAS}

\section{Patient selection \& surgical considerations}

The optimal approach for symptomatic tuberculum sellae meningiomas remains controversial. While conventional transcranial approaches are still widely used, minimally invasive "keyhole" approaches are increasingly applied, but the ideal approach remains debated ${ }^{[1,13,20-27]}$. We and others have used the endoscopic endonasal approach and supraorbital "eyebrow" approach, depending on certain tumor characteristics for over 15 years. In our initial experience addressing this topic published in 2009 and using an endoscope-assisted method, we concluded the endonasal route was preferred for smaller meningiomas that did not extend beyond the supraclinoid internal carotid arteries (ICAs), while larger tumors that extended more laterally were appropriate for supraorbital removal ${ }^{[11]}$. During this time period, we approached $75 \%$ of tuberculum sellae meningiomas by the supraorbital approach and $25 \%$ by an endoscope- 
assisted endonasal approach. Since 2009, we have transitioned to a fully endoscopic endonasal approach while gaining more experience with the supraorbital route for parasellar tumors and have reversed the ratio to $61 \%$ endoscopic endonasal and $39 \%$ supraorbital route r,10,28-30] $_{\text {. }}$

There are several major advantages of the endonasal route. The natural nasal corridor provides a direct trajectory to the tuberculum sellae and posterior planum, facilitating tumor removal with minimal brain manipulation. The meningioma lies between the surgeon and critical structures such as the optic nerves, optic chiasm and ICAs, thereby minimizing risk of iatrogenic injury. Medial optic canal decompression can be safely and effectively performed when optic canal invasion is present. Devascularization is accomplished early in surgery by interrupting the dural blood supply during the approach. Finally, adjacent hyperostotic bone is readily removed en route to the meningioma.

When selecting patients for an endoscopic endonasal transplanum/transtuberculum approach, the following factors are considered favorable: $(1)$ smaller $(\leq 3 \mathrm{~cm})$, relatively midline tumors with minimal-tono lateral extension beyond the supraclinoid ICAs; (2) the majority of tumor below the planum; (3) presence of tuberculum sellae hyperostosis; (4) relatively acute tuberculum angle (less than $135^{\circ}$ ); and (5) unilateral or bilateral medial optic canal invasion [Figure 1]. The endonasal corridor has limited access lateral to the supraclinoid ICAs, so gross total removal of larger tumors, or those with further lateral extension, may not be possible. When the majority of the tumor lies below the level of the planum sphenoidale, a portion of the tumor will often not be visible with a transcranial approach. In contradistinction, the endonasal approach affords a direct view of the sella, enabling complete tumor resection. This is especially true in the presence of a relatively acute tuberculum angle. Similarly, hyperostosis of the tuberculum sellae may further limit visualization of the inferior aspect of the tumor in a transcranial approach, so an endonasal approach should be favored when this feature is present. Finally, optic canal invasion often occurs along the inferomedial aspect of the canal. Transcranial approaches are limited in their ability to access this region on the ipsilateral side. However, bilateral optic canal decompression is easily performed from an endonasal approach. Direct visualization of the tumor invading the optic canals is obtained, enabling safe removal. In our experience, $71 \%$ of patients with vision deficits experienced objective improvement after an endoscopic endonasal transplanum/transtuberculum approach for meningioma, with no instances of vision worsening ${ }^{[30]}$.

In addition to the aforementioned factors, several important pre-operative considerations should be made. The surgical goal must be clearly defined a prior. Vascular encasement should be identified, with a consideration for subtotal resection or transcranial approach if present. Similarly, optic nerve encasement is generally not conducive to achieving gross total resection. A conchal or presellar sphenoid sinus pneumatization pattern may make identification of critical landmarks difficult. A medial course of the cavernous, clinoid or supraclinoid segments of the ICAs may significantly limit the surgical corridor. The endonasal approach creates a large dural defect requiring a robust skull base reconstruction, ideally with a pedicled nasoseptal flap and multilayered reconstruction. Thus, careful planning is required for all patients, particularly those at a high risk of cerebrospinal fluid (CSF) leak, such as patients with high body mass index, uncontrolled diabetes, previous surgery and/or previous radiation therapy.

The goals of surgery for the endoscopic endonasal transplanum/transtuberculum approach for tuberculum sellae meningiomas are: (1) maximal safe resection; (2) decompression of the optic apparatus when applicable; (3) preservation and/or restoration of normal pituitary gland function; (4) effective reconstruction of the skull base; and (5) avoidance of complications. 


\author{
Anatomical Factors Favoring Endonasal Approach: \\ 1. Majority of tumor below planum \\ 2. Tuberculum angle $<135$ degrees \\ 3. Minimal to no lateral extension beyond supraclinoidal ICAs \\ 4. Presence of hyperostotic tuberculum \\ 5. With or without medial optic canal invasion
}

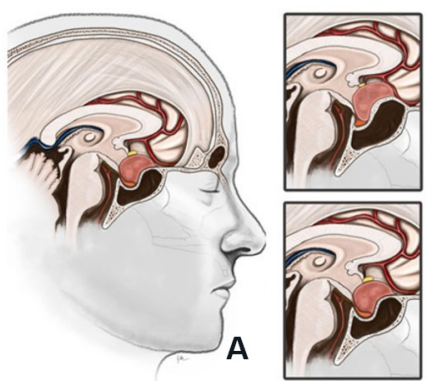

Anatomical Factors Favoring Supraorbital Approach:

1. Majority of tumor above planum

2. Tuberculum angle $>135$ degrees

3. Larger tumor with lateral extension beyond supraclinoidal ICA

4. No medial optic canal invasion

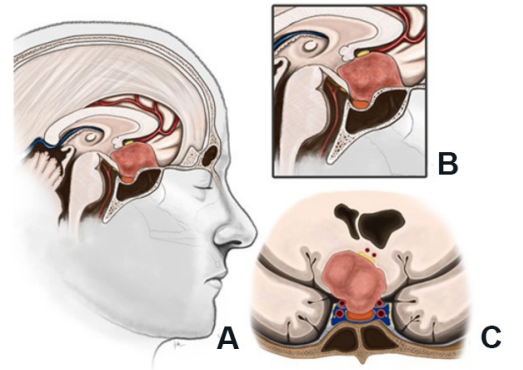

Anatomical Factors for Either Endonasal or Supraorbital Approach:

1. Similar portion of tumor above and below planum

2. Minimal to no lateral extension beyond supraclinoid ICAs

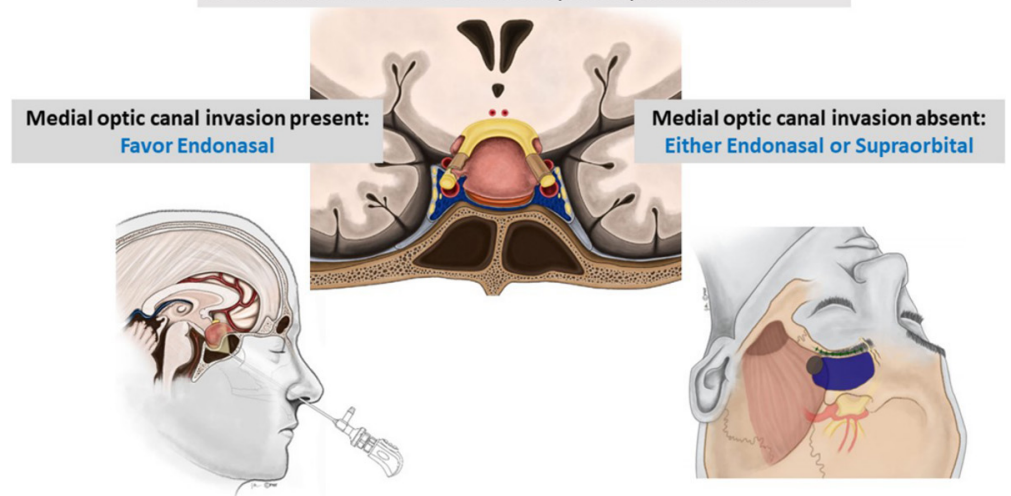

Figure 1. Algorithm for approaching tuberculum sella meningiomas with 4 possible scenarios. In A the endonasal route is preferred; in B the supraorbital is favored, and in C either approach may be reasonable based on tumor location, parasellar anatomy and presence or absence of optic canal invasion. Overall, a slight majority of these tumors are now approached by the endonasal given a high propensity of tuberculum meningiomas to invade one or both medial optic canals. ICAs: Internal carotid arteries.

\section{Pre-operative management}

Patients considered for surgery should undergo a detailed history and neurological exam. This evaluation should include assessments of mental status, cranial nerve function, visual acuity, visual fields, dilated fundoscopic evaluation, optical coherence tomography, comprehensive endocrinological evaluation (if the tumor encroaches on the sella) and endoscopic nasal examination. Thin slice CT is recommended to 
evaluate the relevant paranasal sinus and skull base bony anatomy, sphenoid sinus pneumatization pattern, areas of dehiscence and presence of hyperostosis. MRI should be thoroughly examined for tumor origin, extension, and localization critical structures in relation to the tumor such as the optic nerves and chiasm, ICAs and their branches, pituitary gland and infundibulum. Either CT or MR angiography may be indicated for tumors that encase the vasculature for the purposes of surgical planning [Figures 2-4].

\section{Surgical technique}

At our center, the endoscopic endonasal transplanum/transtuberculum approach is performed as a binostril technique with a neurosurgeon and otolaryngologist working together throughout the majority of the procedure. The operation is begun with a $4 \mathrm{~mm} 0^{\circ}$ rigid high-definition endoscope, with $30^{\circ}$ and $45^{\circ}$ endoscopes available for use later in the procedure. Surgeon ergonomics are addressed by positioning a high-definition monitor directly in front of each surgeon. A third monitor for neuronavigation is placed between the 2 high-definition monitors [Figure 5]. Surgical steps are detailed in Video 1.

\section{Patient positioning}

The patient is positioned supine with the head tilted toward the left shoulder and turned $20^{\circ}$ to $30^{\circ}$ toward the right. For an approach to the planum sphenoidale/tuberculum sellae, $10^{\circ}$ to $15^{\circ}$ of extension is used and the head is fixed in the three-point Mayfield cranial fixation system. Optical neuronavigation is registered and leads for somatosensory evoked potential monitoring are placed. The right lower quadrant of the abdomen is prepped for a fat graft harvest.

\section{Nasal preparation and approach}

The nasal cavity is prepared prior to beginning the approach by spraying oxymetazoline in both nares. The face, perinasal area, and right lower abdominal area (for fat graft harvesting) are then prepped and draped in a sterile fashion. We have recently implemented a nasal rinse with a betadine solution diluted 1:1 with normal saline to minimize the risk of COVID-19 transmission.

The initial approach into the sphenoid sinus is performed by the otolaryngologist with the $0^{\circ}$ endoscope. Lidocaine $1 \%$ with 1:100,000 epinephrine is first injected into the middle turbinates and posterior nasal septum bilaterally. Both inferior turbinates are first in-fractured then out-fractured. Similarly, the middle turbinates are out-fractured, exposing the sphenoid ostia. Next, monopolar electrocautery with a curved microtip is used to make a unilateral mucoperiosteal incision beginning immediately inferior to the sphenoid ostium and extending to a point approximately $2 \mathrm{~cm}$ anteriorly, along the inferior vomer and posterior nasal septum, before turning superiorly towards the olfactory groove [Figure 6]. The rescue flap is elevated inferiorly and the septal olfactory strip above is elevated superiorly, preserving the olfactory fibers. A nasoseptal flap is harvested on the contralateral side, ensuring the preservation of the septal olfactory strip by using a similar mucoperiosteal incision that is carried laterally into the inferior meatus to harvest a sufficiently wide flap. The nasoseptal flap is placed in the nasopharynx and kinking of the vascular pedicle is avoided.

Next, a posterior septectomy is performed to connect the right and left nasal cavities. An attempt is made to remove the bone in one piece to preserve the bone for skull base reconstruction. A wide sphenoidotomy is then performed that extends lateral to the sphenoid ostia and generally to the floor of the sphenoid sinus inferiorly and to the roof of the sphenoid/ethmoid junction superiorly. Using a $30^{\circ}$ endoscope, the ethmoid air cells are opened bilaterally to expose the laminae papyraceae and each septal olfactory strip is lateralized along their respective fovea ethmoidalis. All mucosa of the sphenoid sinus is removed to facilitate adherence of the nasoseptal flap at the conclusion of the procedure. 

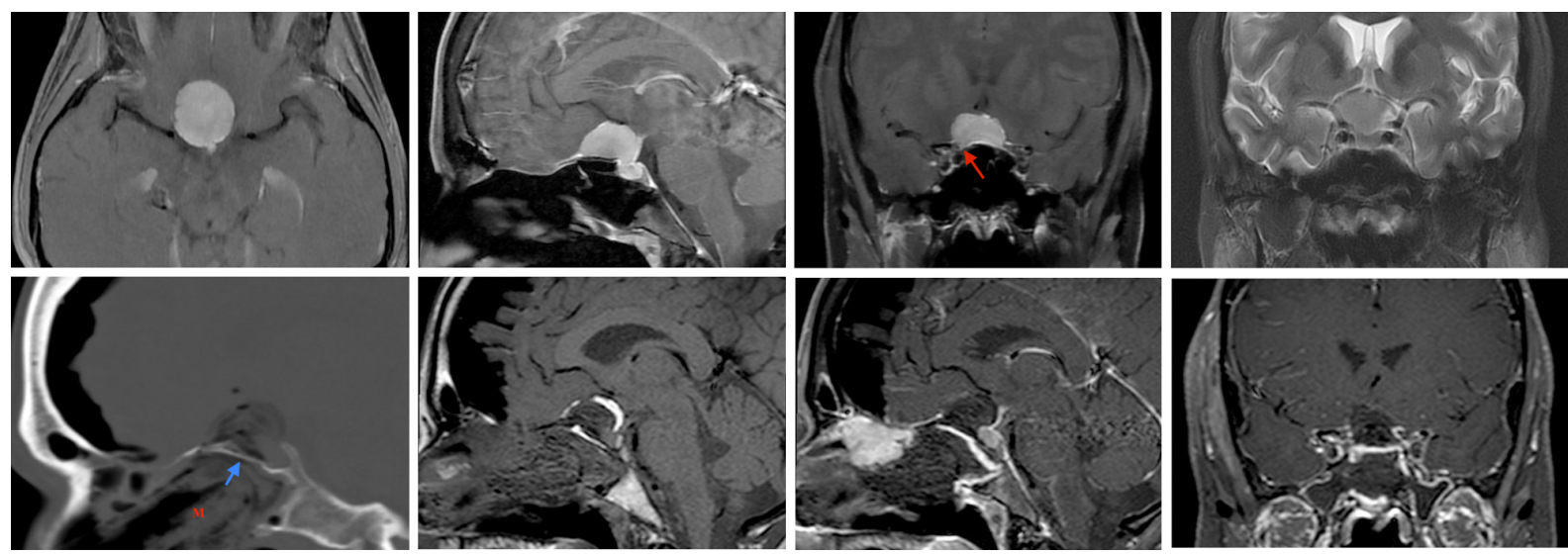

Figure 2. A 52-year-old woman presented with progressive bilateral vision loss, right worse than left, over three years. (Top row) Preoperative imaging demonstrates a large tuberculum sellae/posterior planum meningioma with extension into the sella. Bilateral optic canal invasion is seen, right more than left (red arrow). There is no supraclinoid carotid artery encasement, or lateral extension. The pituitary infundibulum is displaced posteriorly. An endoscopic transtuberculum/transplanum approach was performed. (Bottom row) Post-operative imaging shows gross total resection. Sagittal CT and MRI demonstrates nasal packing up ("M") to the bony buttress (posterior nasal septum graft; blue arrow) with fat graft and collagen sponge in the resection cavity and a well-vascularized nasoseptal flap is in place with pituitary gland and infundibulum enhancing normal. Within 2 weeks of surgery her visual field deficit resolved, and visual acuity remained stable. See Video 1.
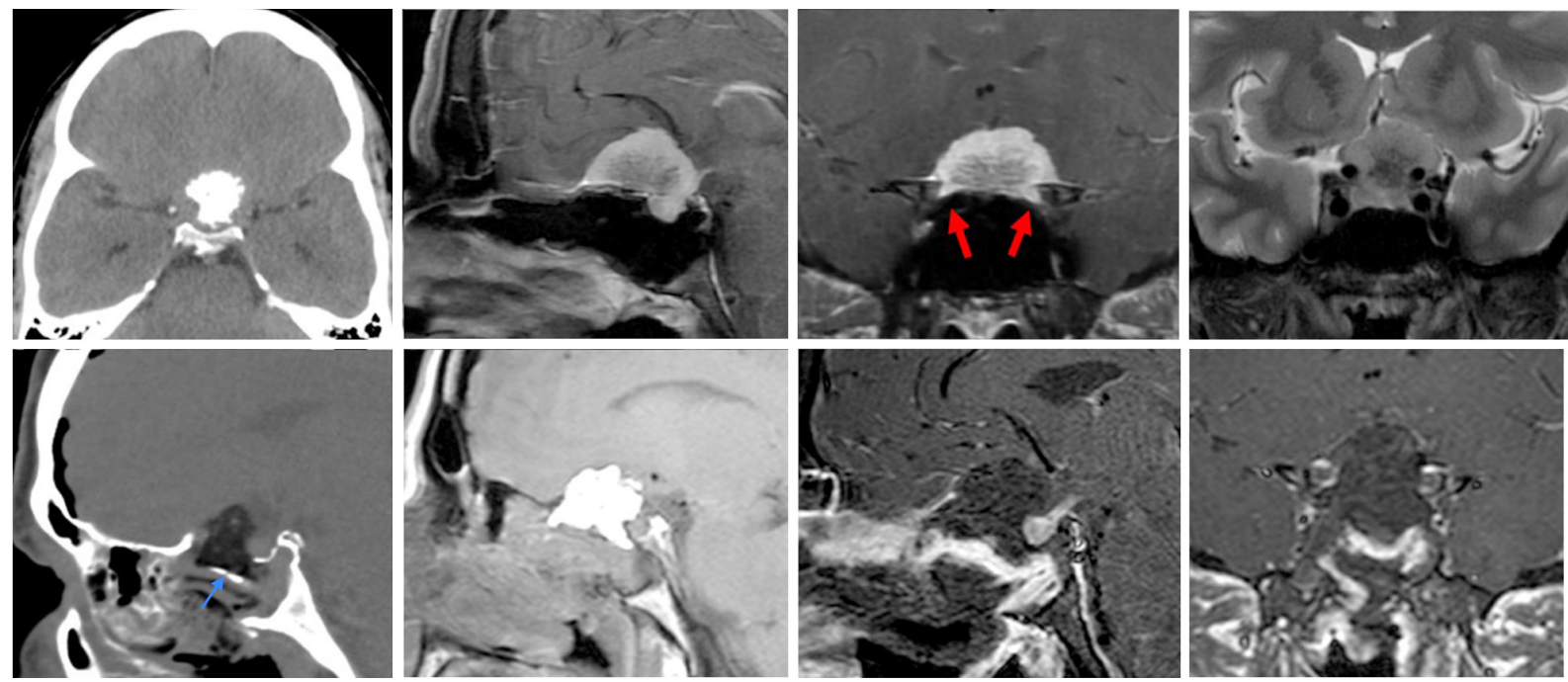

Figure 3. A 39-year-old man presented with progressive left eye vision loss over several months. Pre-operative imaging demonstrates a large, calcified tuberculum sellae/planum meningioma with extension into the sella. Bilateral optic canal invasion is seen, left more than right (red arrows). The left internal carotid artery is encased, with significant encroachment upon the right carotid artery. An endoscopic transtuberculum/transplanum approach was performed without complication. Post-operative MRI demonstrates gross total resection. A fat graft is in the resection cavity with a well-vascularized nasoseptal flap over a bony buttress (posterior nasal septum graft; blue arrow). The pituitary gland and infundibulum enhance normally.

\section{Bone removal}

Once the sphenoid sinus has been entered, any bony septations are carefully removed using a rongeur or high-speed drill with a $4 \mathrm{~mm}$ course diamond bit. Special attention is paid to lateral septations as they often lead directly to the petrous and cavernous carotid arteries. Aggressive removal or torqueing of these septations is avoided as such maneuvers can result in carotid artery laceration. At this stage, several important landmarks should be identified using the $30^{\circ}$ endoscope, including the optic and carotid prominences, lateral opticocarotid recess (OCR; corresponding to the optic strut), medial OCR (delineating 

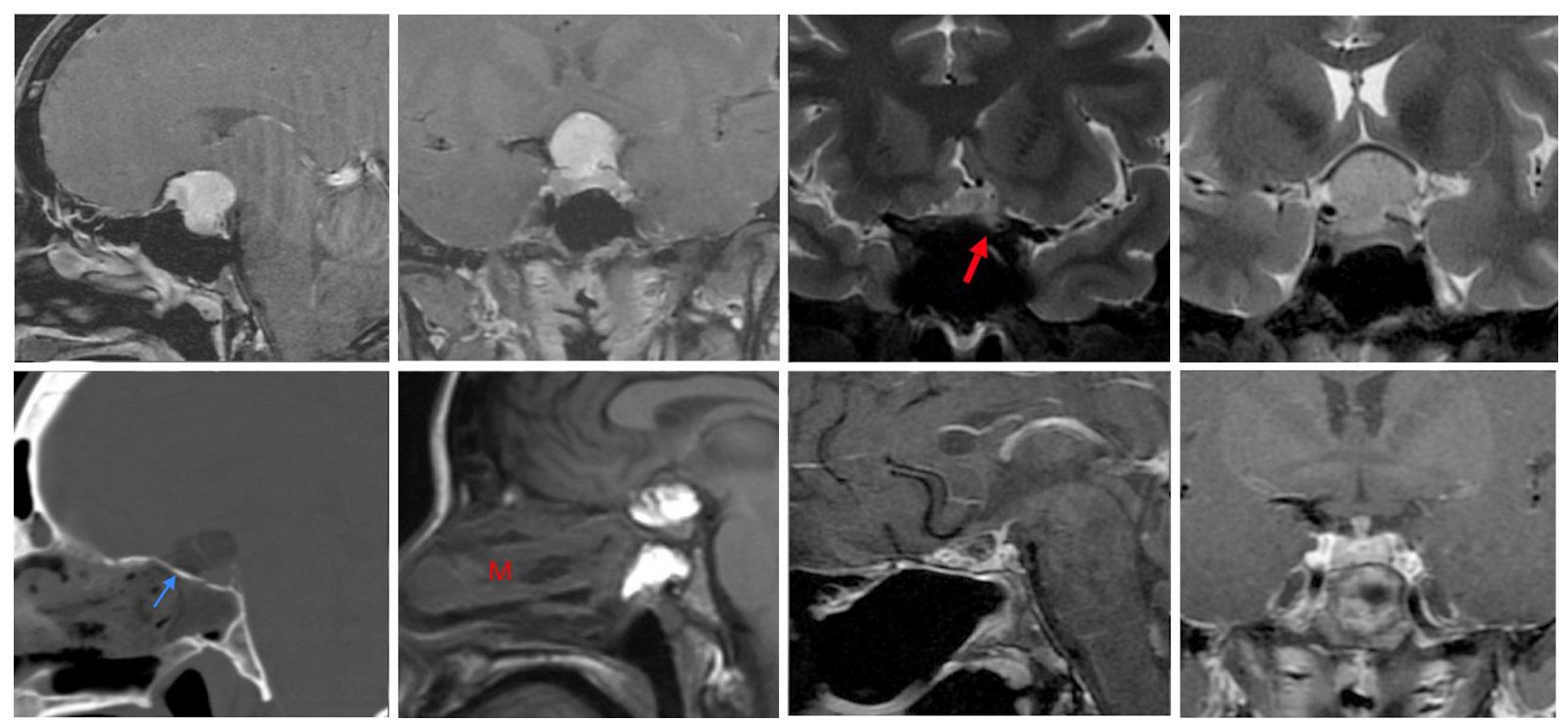

Figure 4. A 46-year-old woman presented with severe left eye vision loss and progressively worsening right eye vision, with a right inferior field cut. She also had amenorrhea with mild hyperprolactinemia, presumably from stalk effect. Pre-operative imaging demonstrates a large tuberculum sella meningioma with a severely displaced optic apparatus and left optic canal invasion (red arrow), but no arterial encasement or lateral extension beyond the supraclinoid ICAs. The pituitary infundibulum is displaced posteriorly. An endoscopic transtuberculum approach was performed with a gross total resection achieved. A sellar fat graft and well-vascularized nasoseptal flap is seen overlying a bony buttress (posterior nasal septum graft; blue arrow) reinforced with nasal packing (" $M$ "). The pituitary gland and infundibulum enhance normally. The patient demonstrated marked improvement in visual acuity and visual fields and her menses returned with normalization of serum prolactin.

the lateral aspect of the sella), clival recess, tuberculum sellae and planum sphenoidale. These structures should be verified with neuronavigation and the micro-Doppler probe used to identify the ICAs. The bone of the sellar face, tuberculum sella and the planum sphenoidale is then thinned with the drill to expose the dura. Kerrison rongeurs are used to remove the thinned bone. The sagittal extent of exposure depends on the size of the meningioma and should extend from the sella (but leaving an inferior lip or shelf of sellar bone to aid in reconstruction) to just beyond the anterior edge of the tumor on the posterior planum. The coronal exposure should be from medial OCR to medial OCR, with wide exposure of the planum sphenoidale. If there is extension into one or both optic canals, these should be unroofed. A $3 \mathrm{~mm}$ hybrid diamond bit with irrigating sheath is used and then once the proximal canal bone is "egg-shelled", it is further opened with a $1 \mathrm{~mm}$ Kerrison rongeur working in the proximal-to-distal direction.

\section{Dural opening}

Prior to dural opening, the location of the ICAs is precisely determined with a micro-Doppler probe and surgical navigation. Next, the dural "footprint" of the tumor from just above the diaphragma sellae to its anterior extend on the posterior planum is lightly cauterized with the bipolar for initial tumor devascularization. The dura is then opened in rectangular fashion over the tumor epicenter with horizontal dural cuts made along the top of the pituitary gland and just below the circular sinus (which is cauterized and cut) and at the anterior tumor edge. The lateral dural cuts are then made and connected with the supradiaphragmatic incision, and the dural window is removed.

\section{Tumor removal}

The meningioma is then internally debulked, typically with sharp dissection using microscissors, tumor grasping forceps and the ultrasonic aspirator. Most meningiomas are too fibrous for use of ring curettes. We generally begin mobilizing the tumor capsule from the adjacent arachnoid anteriorly as there are generally 


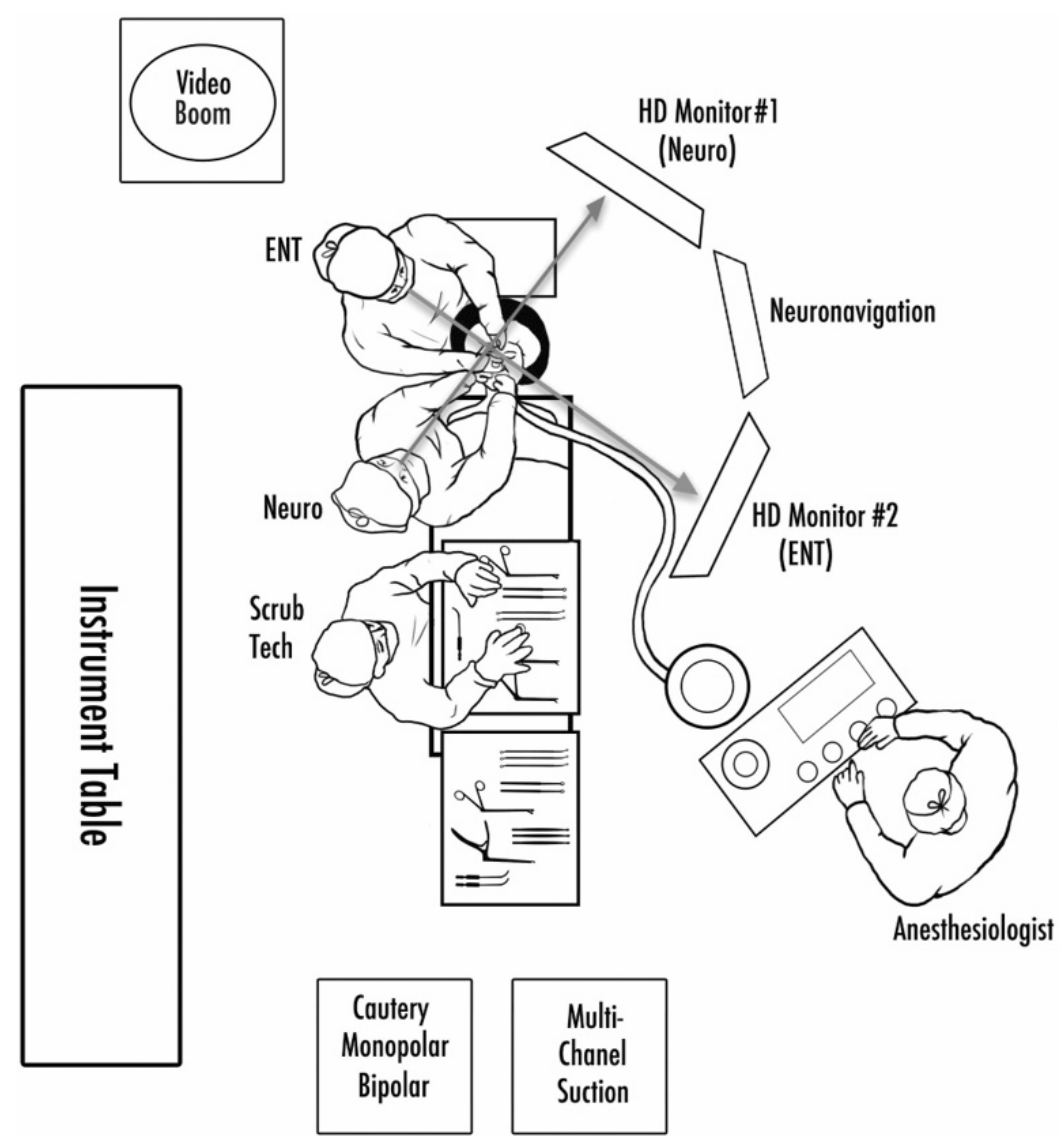

Figure 5. Diagram of the operating room setup for endoscopic endonasal surgery. The procedure involves an otolaryngologist and neurosurgeon, both positioned on the patient's right side. Ergonomics are optimized by having an endoscope monitor positioned directly in front of each surgeon as well as an arm rest for the otolaryngologist's left arm, holding the endoscope.

no critical structures in this location. Using sharp dissection and preserving the arachnoid planes, the tumor capsule is methodically dissected away from the overlying frontal lobe. After the initial tumor debulking, it is also helpful to identify the superior surface of the pituitary gland and infundibulum to avoid injuring these structures. To achieve this view, the inferior pole of the tumor, which is often attached to the diaphragma sellae, is detached and progressively removed. The infundibulum will lie posterior and inferior to the tumor. The paired superior hypophyseal arteries and their branches going to the optic chiasm are also preserved. Subsequently, the tumor pseudocapsule is gently pulled inward and arachnoid bands between the tumor, optic apparatus and the superior hypophyseal arteries are cut sharply. The optic chiasm may be markedly post-fixed (pushed posteriorly) or lifted superiorly and posteriorly. Progressive internal tumor debulking will allow the optic chiasm and optic nerves to be progressively visualized. With further medial mobilization and removal of the most lateral tumor capsule, the distal optic nerves will become visualized. Frequent removal of freed tumor capsule is paramount to maintain optimal visualization of the optic apparatus. The anterior cerebral arteries and branches should be anticipated, and their shifting location confirmed frequently with the micro-Doppler probe as the tumor debulking progresses, given that neuronavigation becomes less accurate after initial tumor removal and brain shift. If anterior cerebral artery (ACA) branches or the supraclinoid ICA itself is partially encased by meningioma, it is often best to leave small tumor remnants behind to avoid a major vascular injury and stroke, particularly in older patients and those with cardiovascular disease. 


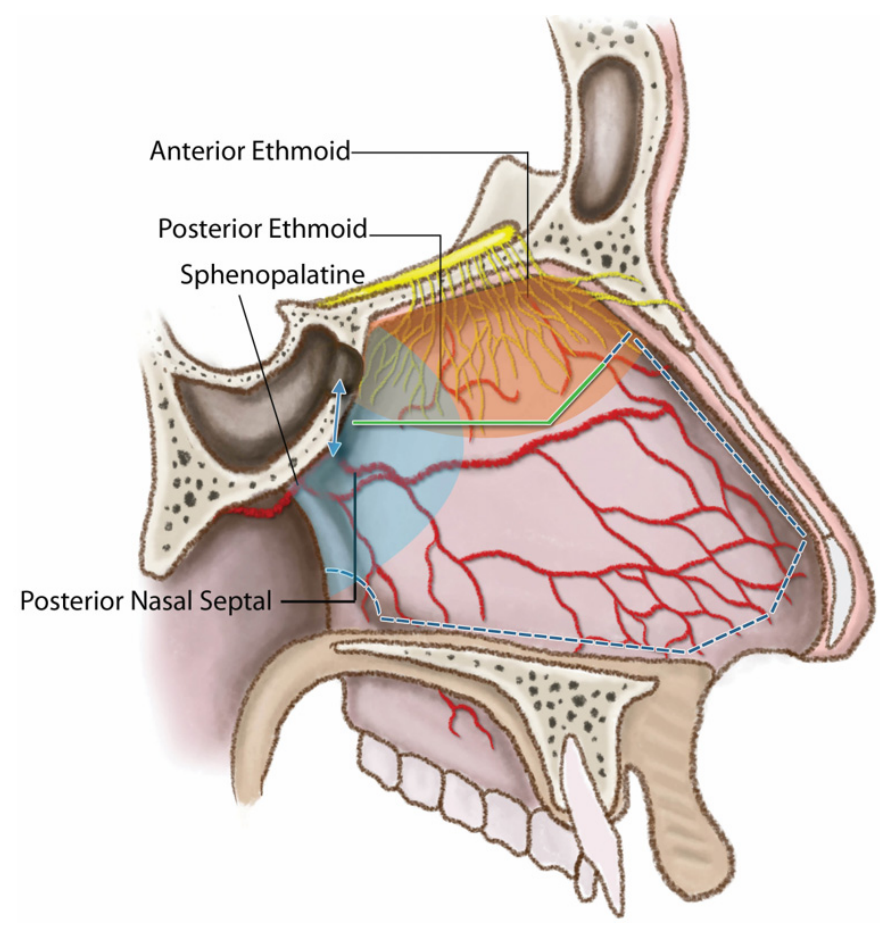

Figure 6. Lateral view of the nasal septum depicting the mucosal cut made for elevating a nasoseptal flap (dashed line) during an endoscopic transtuberculum/transplanum approach, preserving olfaction by sparing the septal olfactory strip above which contains the olfactory nerve fibers. A rescue flap incision (solid line) is made on the other side, again aimed at preserving olfaction.

If there is meningioma growth into one or both optic canals, this tumor may be addressed once the majority of the tumor has been resected. The bone of the medial aspect of the optic canal should be decompressed as described above. Then, using a hook knife, the optic nerve sheath can be opened from medial to lateral once the ophthalmic artery takeoff has been visualized infero-medially. A $45^{\circ}$ endoscope may be helpful at this stage to clearly visualize and achieve maximal tumor removal within the medial optic canals.

\section{Skull base reconstruction}

Once tumor removal is complete, the resection cavity is irrigated with warm saline and hemostasis is achieved. By definition, a high flow, Grade 3 CSF leak will be present due to dural resection ${ }^{[31]}$. Sufficient abdominal fat is harvested to fill the intracranial dead space, taking care not to recreate too much mass effect on the optic apparatus. The fat is followed by an extradural layer of collagen sponge extending only 1$2 \mathrm{~mm}$ beyond the bony edges of the surgical corridor; this placement allows maximal contact of the nasoseptal flap with the bone around the defect. Ideally, harvested septal bone (or alternatively a synthetic buttress) is carefully wedged from the inferior sellar lip to the antero-superior defect within the bony defect. The nasoseptal flap is then rolled over the bony skull base defect with care being taken to ensure there is no redundancy or folds in the flap. The flap should fully cover the defect and extend beyond its edges as far as possible with maximal contact on the bone adjacent to the defect. Additional fat is placed over the flap followed by an outer layer of collagen sponge and tissue glue. An additional layer of collagen sponge is placed over the fat graft and then reinforced with unilateral or bilateral Merocel (Medtronic, Dublin, Ireland) sponges placed under direct visualization. The patient remains on antibiotics for the 5 days while the Merocel sponges remain in place and then are removed under direct visualization. While the optimal duration of nasal packing is debated, based on our experience, 5 days appears to be sufficient to ensure adherence of the reconstruction to the skull base ${ }^{[31]}$. We have experienced no instances of sinonasal infection. A nasogastric tube is briefly placed to empty the stomach contents to minimize the risk of post- 
operative emesis. Similarly, total intravenous anesthesia with propofol is used with a smooth emergence from anesthesia to avoid post-operative emesis and "bucking" on the endotracheal tube during extubation $^{[32]}$. In our experience, lumbar drainage is not necessary to ensure effective reconstruction ${ }^{[31]}$.

Should a nasoseptal flap not be available, other vascularized flaps may be considered such as a pedicled middle or inferior turbinate flap or pericranial flap tunneled through a nasionectomy ${ }^{[33,34]}$. In cases with no available vascularized options, multilayered avascular reconstructions with autologous fat, fascia lata and synthetic materials reinforced with Merocel (Medtronic, Dublin, Ireland) sponges may be required, although CSF leak rates tend to be higher compared to vascularized reconstruction techniques ${ }^{[35]}$.

An important aspect of skull base reconstruction to be stressed is to utilize a protocol based on the degree of intra-operative CSF leak. Planning the reconstruction, including back-up options, prior to surgery and adjusting as necessary based on intra-operative findings will help ensure a low post-operative CSF leak rate of less than $5 \%$ and hopefully much lower, even for high-grade leaks encountered in anterior cranial fossa surgery ${ }^{[31]}$.

\section{Outcomes}

Recent series have indicated overall excellent visual outcomes for tuberculum sellae meningiomas approached by the endonasal route [Table 1] ${ }^{[13,24,26,36-43]}$. Yang et al. ${ }^{[19]}$ performed a meta-analysis of studies assessing the endonasal endoscopic route $v s$. transcranial approaches for tuberculum sellae meningiomas and found higher rates of visual improvement $(85.7 \%$ vs. $55.1 \%)$ in the endoscopic cohort with similar rates of gross total resection ( $74.5 \%$ vs. $76.1 \%$ ). CSF leak rates were significantly higher in the endoscopic cohorts ( $8.6 \%$ vs. $2.1 \%$ ), although we have recently published a CSF leak grading scale and recommended skull base reconstruction protocol that has resulted in a CSF leak rate of only $2 \%$ ( 1 of 49 patients) of patients with high flow (Grade 3) CSF leaks ${ }^{[31]}$. A recent meta-analysis has demonstrated a significant decrease in CSF leak rate over time to $4 \%$ with the endoscopic endonasal approach, reported in the last 5 years $^{[44]}$.

In 2020, Youngerman et al. ${ }^{[45]}$ published a resectability scoring system to predict gross total resection for planum sphenoidale and tuberculum sellae meningiomas using the endoscopic endonasal route. One point is assigned to each of the following: (1) prior surgery; (2) complete ICA encasement on more than 1 MRI plane; and (3) lateral extension of the tumor beyond the lateral margin of either optic nerve. Using their case series of 51 operations, they found that scores of 0,1 and 2 were associated with gross total resection rates of $97 \%, 54 \%$ and $12.5 \%$, respectively. They found that tumor size, medial optic canal involvement, brain edema and encasement of the anterior cerebral arteries were not predictive of gross total resection.

\section{Complications}

While endoscopic endonasal surgery places the tuberculum sellae/planum sphenoidale meningioma in direct line of site, the surrounding critical structures may be at risk of iatrogenic injury as the tumor may be quite adherent to these structures or encase them. Thorough pre-operative planning, in addition to the diligent use of neuronavigation and micro-Doppler probe, is highly recommended to minimize risks of complications. Injury to the ICA and ACA should be immediately investigated to find the bleeding site with an attempt to repair with clip ligation, tamponade with muscle tissue or synthetic material, or sacrifice of the parent vessel as deemed necessary. Once the bleeding has been stabilized, the procedure should be aborted, and the patient is brought to the angiography suite for evaluation and treatment of arterial injury and/or pseudoaneurysm formation. At our institution, we have implemented a "carotid injury timeout" in conjunction with a standard operative timeout for high-risk procedures. Additional equipment is made available in the room to deal with a major arterial injury, including essential instruments, backup equipment, medications and crossmatched blood. The neuro-interventional team is notified prior to the 
Table 1. Demographics and outcomes for recent case series of endoscopic transsphenoidal/transplanum approach for tuberculum and posterior planum meningiomas

\begin{tabular}{|c|c|c|c|c|c|c|c|c|c|c|}
\hline Ref. & Year & $\mathbf{N}$ & $\begin{array}{l}\text { Female } \\
(\%)\end{array}$ & $\begin{array}{l}\text { Arterial } \\
\text { encasement } \\
(\%)\end{array}$ & $\begin{array}{l}\text { OC } \\
\text { invasion } \\
(\%)\end{array}$ & $\begin{array}{l}\text { Vision } \\
\text { symptoms } \\
(\%)\end{array}$ & $\begin{array}{l}\text { Post-op } \\
\text { vision } \\
\text { improvement } \\
(\%)\end{array}$ & $\begin{array}{l}\text { GTR } \\
(\%)\end{array}$ & $\begin{array}{l}\text { Complications } \\
\text { (\%) }\end{array}$ & $\begin{array}{l}\text { Recurrence } \\
\text { (\%) }\end{array}$ \\
\hline Khan et al..$^{[42]}$ & 2014 & 17 & 76 & NR & NR & 82 & 64 & 65 & $\begin{array}{l}\text { CSF leak: } 12 \\
\text { Hypopituitarism: } \\
6\end{array}$ & NR \\
\hline Koutourousiou et al. ${ }^{[13]}$ & 2014 & 75 & 81 & 25 & 27 & 81 & 79 & 76 & $\begin{array}{l}\text { CSF leak: } 25 \\
\text { Meningitis: } 5 \\
\text { Vision loss: } 4 \\
\text { Stroke: } 1\end{array}$ & 5 \\
\hline Ottenhausen et al. ${ }^{[36]}$ & 2014 & 20 & 70 & NR & NR & 85 & 82 & 80 & $\begin{array}{l}\text { CSF leak: } 10 \\
\text { Infection: } 5 \\
\text { PE: } 5\end{array}$ & 10 \\
\hline Hayhurst et al. ${ }^{[43]}$ & 2016 & 10 & 70 & NR & 80 & 40 & 0 & 60 & CSF leak: 0 & NR \\
\hline Linsler et al. ${ }^{[41]}$ & 2017 & 6 & 100 & 16 & NR & 50 & 67 & 83 & CSF leak: 0 & 16 \\
\hline Bander et al. ${ }^{[26]}$ & 2018 & 17 & 65 & NR & NR & 88 & 67 & 82 & CSF leak: 12 & NR \\
\hline Elshazly et al. ${ }^{[38]}$ & 2018 & 25 & 84 & $\begin{array}{l}\text { ACA: } 12 \\
\text { ICA: } 32\end{array}$ & 68 & 80 & 88 & 76 & $\begin{array}{l}\text { CSF leak: } 8 \\
\text { Hematoma: } 4 \\
\text { PE: } 4\end{array}$ & 0 \\
\hline Kong et al. ${ }^{[24]}$ & 2018 & 84 & 76 & NR & 94 & 95 & 85 & 83 & $\begin{array}{l}\text { CSF leak: } 5 \\
\text { Meningitis: } 7 \\
\text { Vision loss: } 5\end{array}$ & NR \\
\hline Song et $a{ }^{[37]}$ & 2018 & 44 & NR & 25 & 77 & 100 & 98 & 84 & $\begin{array}{l}\text { CSF leak: } 0 \\
\text { Meningitis: } 3 \\
\text { Vision loss: } 36 \\
\text { ICA injury: } 3 \\
\text { Permanent DI: } 3 \\
\text { Hypopituitarism: } \\
5 \\
\text { Hematoma: } 5\end{array}$ & 15 \\
\hline Zoli et al. $^{[39]}$ & 2018 & 42 & NR & NR & NR & $\begin{array}{l}\text { VA: } 67 \\
\text { VF: } 57\end{array}$ & $\begin{array}{l}\text { VA: } 68 \\
\text { VF: } 75\end{array}$ & 83 & $\begin{array}{l}\text { CSF leak: } 19 \\
\text { Stroke: } 2\end{array}$ & 5 \\
\hline Salek et al..$^{[40]}$ & 2020 & 8 & 63 & 13 & 50 & 100 & 88 & 75 & CSF leak: 25 & 13 \\
\hline
\end{tabular}

ACA: Anterior cerebral artery; CSF: cerebrospinal fluid; DI: diabetes insipidus; GTR: gross total resection; ICA: internal cerebral artery; N: number; NR: not reported; OC: optic canal; PE: pulmonary embolism; VA: visual acuity; VF: visual field.

operation.

Meticulous dissection of the optic nerves and chiasm, including careful preservation of small perforators to the optic apparatus, including the superior hypophyseal arteries, is required to prevent post-operative vision decline. Endoscopic endonasal series have reported worsening vision in up to $36 \%$, with more recent series reporting much lower rates of less than $5 \%$ [Table 1] $]^{[1,13,23,24,26,36-43,45-51]}$. CSF leaks from this approach are high flow (Grade 3 leaks) requiring a robust reconstruction, ideally with a nasoseptal flap. As outlined above, we have recently published our skull base reconstruction protocol which has resulted in a CSF leak rate of $2 \%$ for high flow (Grade 3) leaks ${ }^{[31]}$.

Other complications include permanent post-operative anterior endocrinopathy or diabetes insipidus (6.6\%), intracranial hemorrhage $(0.7 \%)$ and dysosmia $(21.9 \%)^{[19]}$. Importantly, we utilize a nasoseptal flap harvest technique that preserves the septal olfactory strips located in the superior portion of the nasal septum, thus preserving olfaction in greater than $97 \%$ of patients ${ }^{[52]}$. 


\section{TRANSCRIBRIFORM APPROACH TO PLANUM \& OLFACTORY GROOVE MENINGIOMAS}

\section{Patient selection \& surgical considerations}

The endoscopic endonasal transcribriform approach is an effective way to approach olfactory groove meningiomas as it provides direct access to the anterior cranial fossa floor dura and the feeding arteries. Other advantages over tradition transcranial trajectories include lack of brain retraction, increased possibility of Simpson grade 1 resection and excellent visualization of surrounding critical structures. However, loss of olfaction is virtually guaranteed in this approach due to disruption of the olfactory fibers traversing the cribriform plate. Furthermore, the anatomical limitations are well defined, restricting the use of this approach to a subset of patients with smaller olfactory meningiomas. The orbits limit access laterally, although the lamina papyracea can be removed and gentle displacement of the periorbita provides access to the midorbital sagittal plane. Tumor involvement superiorly along the posterior wall of the frontal sinus becomes increasingly difficult to visualize and reach. Careful patient selection with thorough evaluation of MRI and CT imaging is required when using this approach to maximize success.

At our center we utilize a supraorbital craniotomy for the great majority of olfactory groove meningiomas as it allows olfaction to be preserved in most cases, with laterality determined by the side with more olfactory nerve involvement to preserve the unaffected olfactory nerve. This approach requires minimal-tono brain retraction, and endoscopes with angled instruments are used in patients with a deep olfactory groove to remove tumor not visualized with the microscope [Figure 7].

\section{Surgical technique}

Patient positioning, approach and bony exposure

The patient is positioned with the head in slight extension similar to the transplanum/transtuberculum approach. The same nasal phase proceeds with harvesting a nasoseptal flap, sphenoidotomy and bilateral ethmoidectomies. One of the middle turbinates is often removed to fully expose the fovea ethmoidalis on either side. Bilateral mastoid antrostomies may be performed to aid in identification of each lamina papyracea. With the use of a $30^{\circ}$ endoscope, mucosa is removed from the superior aspect of the nasal septum and the anterior skull base, and a superior septectomy is performed. With the cribriform plate exposed, the lateral boundaries with the laminae papyraceae are identified, as well as the posterior boundary with the planum sphenoidale. The anterior border with the posterior table of the frontal sinus is identified through the completion of a Draf III procedure with removal of the frontal sinus floor and inferior portion of the interfrontal septum. A prominent frontal beak may need to be removed.

After completely exposing the cribriform plate and each fovea ethmoidalis, the bone is thinned down with a drill. The bony prominences overlying the anterior and posterior ethmoid arteries are identified, carefully thinned and removed. The arteries are then coagulated and divided to avoid an orbital hematoma. A craniectomy is then completed with the drill and Kerrison rongeurs, the boundaries of which are determined by the access required for the meningioma and dural tail. Hyperostotic bone is removed. If removal of the crista galli is required, it is carefully dissected from the falx cerebri.

\section{Tumor removal and skull base reconstruction}

Exposed dura of the anterior cranial fossa is thoroughly coagulated to disrupt blood flow to the meningioma. Lateral incisions are made on each side, followed by an anterior incision with transection of the falx. It is important to cut the falx in a posteroinferior direction to avoid injuring the superior sagittal sinus. An emissary vein through the foramen cecum may be encountered. Finally, a posterior incision is made. Similar to removal of tuberculum sella meningiomas, the tumor is then internally debulked and the capsule gently dissected from the surrounding orbitofrontal cortex using standard microsurgical techniques. 

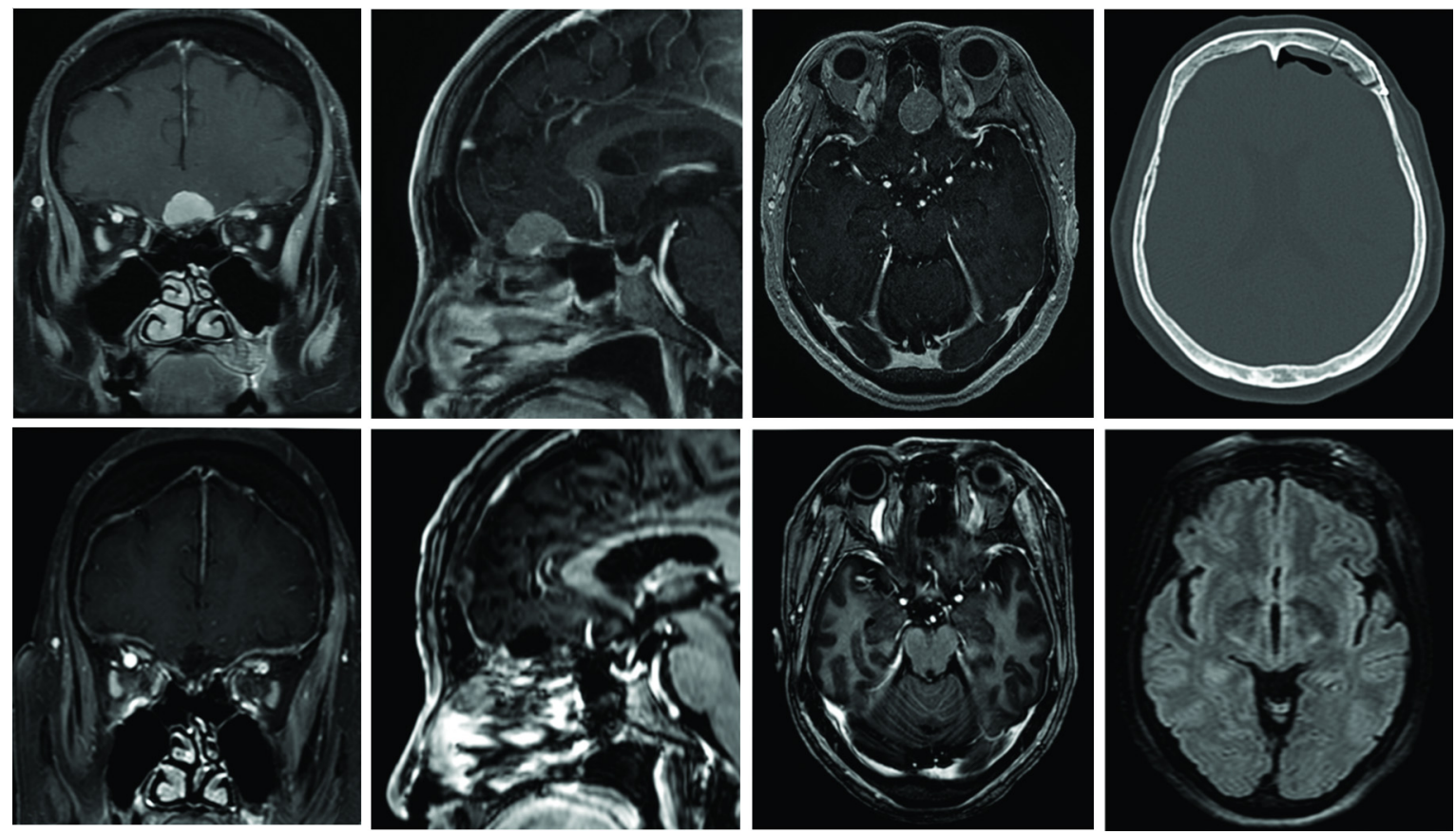

Figure 7. A 68-year-old female presented with progressive periorbital headaches with preserved olfaction. (Top Row) Pre-operative imaging demonstrates an olfactory groove meningioma extending posteriorly to the anterior portion of the planum sphenoidale. The lateral extent of the tumor is confined within the medial aspects of the orbits bilaterally. This tumor is therefore amenable to an endoscopic endonasal transcribriform approach, however, to preserve olfaction we elected to approach this tumor through a left supraorbital eyebrow craniotomy. (Bottom Row) Post-operative imaging demonstrates gross total removal of the meningioma. Top right image shows a post-operative CT scan demonstrating the size of the supraorbital craniotomy. The endoscopic was used to ensure removal of tumor within the depths of the olfactory groove. Axial FLAIR imaging demonstrates no retraction injury to the left frontal lobe. Olfaction was preserved. An endoscopic endonasal trasnscribrifom approach would have guaranteed loss of olfaction and therefore is not the optimal approach.

If there is encasement of the ACAs, early identification posteriorly provides proximal control, and as with tuberculum sellae meningiomas, frequent use of the micro-Doppler probe to map the course of these shifting arteries is recommended.

Effective skull base reconstruction is required due to the inevitable Grade 3 CSF leak and large skull base defect. This reconstruction is performed similarly to the transplanum/transtuberculum approach with a multilayered closure involving a fat graft to fill the dead space, collagen sponge, nasoseptal flap, solid bony or synthetic buttress and tissue glue. A lumbar drain is not used in our practice ${ }^{[31]}$.

\section{Outcomes}

A recent systematic review found that gross total resection of olfactory groove meningiomas through an endoscopic endonasal transcribriform approach was achieved in $69.5 \%$ of patients ${ }^{[53]}$. Comparison studies have consistently reported higher rates of gross total resection with traditional transcranial approaches at approximately $93 \%^{[21,42,43,54-61]}$. While surgeon experience with the transcribriform approach leads to increased rates of gross total resection, tumor size (greater than $4 \mathrm{~cm}$ ), lateral extension beyond the midorbital line, tumor calcifications, significant brain edema and neurovascular encasement limit success. Olfactory groove meningiomas that extend posterior to the optic apparatus may cause visual symptoms, particularly when optic canal invasion is present. In a recent systematic review by Shetty et al. ${ }^{[18]}, 80.7 \%$ of patients with vision symptoms experienced an improvement after endoscopic endonasal surgery, compared to $12.8 \%$ of transcranial approaches. No vision deterioration was reported in the endonasal cohort. Similar to 
tuberculum sellae/planum sphenoidale meningiomas, transcranial approaches are limited in their ability to visualize the inferomedial portion of the ipsilateral optic canal, where tumor invasion generally occurs. Thus, we hypothesize that this discrepancy may be related to excessive manipulation of the optic apparatus and/or insufficient decompression of tumor within the optic canal from above. An endonasal approach provides direct access to the medial $180^{\circ}$ of the optic canals, enabling the opportunity for effective decompression and tumor removal. A summary of recent case series is presented in Table $2^{[3,42,43,55-57,62]}$.

As mentioned previously, loss of olfaction (if not present pre-operatively) is virtually guaranteed with the transcribriform approach due to disruption of the olfactory fibers. This sensory loss has been shown to have a significant impact on quality of life $\mathrm{e}^{[52,63]}$. While a unilateral transcribriform approach has been described to preserve contralateral olfaction, the indications for this technique are highly specific and thus not applicable to the vast majority of patients with olfactory groove meningiomas ${ }^{[64]}$.

\section{Complications}

Aside from loss of olfaction, CSF leak and meningitis are the most common complications. While the rate has decreased with the use of nasoseptal flaps, it remains a challenge for large olfactory groove meningiomas with rates of $26 \%$ to $30 \%$ in the largest series ${ }^{[54,57]}$. Regarding most transcranial approaches for olfactory groove meningiomas, CSF leak rates have ranged from $8.4 \%$ to $10 \%$, while we have recently reported a $1 \%$ CSF leak rate with the supraorbital craniotomy approach ${ }^{[10,58]}$. Other complications reported by Koutourousiou et al ${ }^{[57]}$ include hydrocephalus in $6 \%$, new onset seizures in $4 \%$, meningitis in $2 \%$, cerebral abscess in $6 \%$, and deep venous thrombosis/pulmonary embolism in $20 \%$. A high complication rate is thought to be attributed to the long operative time required for this approach.

\section{CONCLUSION}

Endoscopic endonasal approaches to anterior skull base meningiomas have evolved substantially and are commonly used today at many centers. While the indications are still debated, several advantages exist for the endoscopic route over traditional transcranial approaches, including the ability to remove hyperostotic bone, obtaining direct access to the dura and feeding arteries, minimal brain manipulation, excellent visualization with the endoscope, displacement of critical surrounding structures away from the surgical corridor, and improved vision outcomes with medial optic canal decompression. In our experience and that of others, a majority of tuberculum sellae and posterior planum meningiomas can be safely and effectively removed through an endoscopic endonasal approach, although requisite experience, instrumentation and careful selection of appropriate cases is essential to success. In contrast, a minority of olfactory groove meningiomas are ideally approached from an endonasal route, particularly for those in whom olfaction is already absent, and they do not extend too far laterally. Otherwise, a transcranial route may be most appropriate.

Careful patient selection is paramount to success in removing these anterior skull base meningiomas as there are several important anatomic limitations of the transnasal corridors that must be identified. With modern skull base reconstruction techniques, CSF leak rates are low, particularly for the transplanum/transtuberculum approach. Utilizing endoscopic endonasal routes alongside minimally invasive transcranial approaches, such as the supraorbital keyhole craniotomy, meningiomas of the anterior skull base may be treated effectively with excellent oncological, functional and cosmetic outcomes. Thus, both the endoscopic endonasal and endoscope-assisted supraorbital route should be considered part of the modern surgical armamentarium for these challenging skull base meningiomas. 
Table 2. Demographics and outcomes for recent case series of endoscopic transcribriform approach for olfactory groove meningiomas

\begin{tabular}{|c|c|c|c|c|c|c|c|c|c|}
\hline Ref. & Year & $\mathbf{N}$ & $\begin{array}{l}\text { Female } \\
(\%)\end{array}$ & $\begin{array}{l}\text { Arterial } \\
\text { encasement } \\
(\%)\end{array}$ & $\begin{array}{l}\text { Vision } \\
\text { symptoms } \\
(\%)\end{array}$ & $\begin{array}{l}\text { Post-op vision } \\
\text { improvement } \\
(\%)\end{array}$ & $\begin{array}{l}\text { GTR } \\
(\%)\end{array}$ & $\begin{array}{l}\text { Complications } \\
\text { (\%) }\end{array}$ & $\begin{array}{l}\text { Recurrence } \\
(\%)\end{array}$ \\
\hline Khan et al. ${ }^{[42]}$ & 2014 & 6 & 100 & NR & 33 & 100 & 50 & CSF leak: 33 & 0 \\
\hline Koutourousiou et al. ${ }^{[57]}$ & 2014 & 50 & 64 & $N R$ & 30 & 87 & 67 & $\begin{array}{l}\text { CSF leak: } 30 \\
\text { PE/DVT: } 20 \\
\text { Infection: } 10 \\
\text { Vascular injury: } 2\end{array}$ & 2 \\
\hline de Almeida et al. ${ }^{[56]}$ & 2015 & 10 & 70 & 10 & NR & NR & 70 & $\begin{array}{l}\text { CSF leak: } 10 \\
\text { Meningitis: } 10 \\
\text { MI: } 10\end{array}$ & 10 \\
\hline Banu et al..$^{[55]}$ & 2016 & 6 & 100 & 0 & 17 & 100 & 50 & $\begin{array}{l}\text { CSF leak: } 17 \\
\text { Infection: } 33 \\
\text { Hematoma: } 33 \\
\text { Stroke: } 17 \\
\text { PE/DVT: } 17\end{array}$ & 33 \\
\hline Hayhurst et al. ${ }^{[43]}$ & 2016 & 9 & 89 & NR & NR & NR & 89 & $\begin{array}{l}\text { CSF leak: } 0 \\
\text { Meningitis: } 11\end{array}$ & NR \\
\hline Liu et al. ${ }^{[62]}$ & 2018 & 5 & 80 & 0 & NR & NR & 100 & $\begin{array}{l}\text { CSF leak: } 20 \\
\text { Hematoma: } 20\end{array}$ & 20 \\
\hline Zoli et al. ${ }^{[39]}$ & 2018 & 8 & NR & NR & NR & NR & 63 & CSF leak: 13 & 25 \\
\hline
\end{tabular}

CSF: Cerebrospinal fluid; GTR: gross total resection; MI: myocardial infarction; N: number; NR: not reported; PE/DVT: pulmonary embolism/deep venous thrombosis.

\section{DECLARATIONS}

\section{Acknowledgments}

The authors would like to thank Josh Emerson for his anatomy illustrations presented in this article.

\section{Authors' contributions}

Made substantial contributions to conception and design of the study and performed data analysis and interpretation: Avery MB, Barkhoudarian G, Kelly DF

Performed data acquisition, as well as provided administrative, technical, and material support: Avery MB, Barkhoudarian G, Kelly DF

Availability of data and materials

Not applicable.

\section{Financial support and sponsorship}

None.

\section{Conflicts of interest}

Kelly DF receives royalties from Mizuho Inc.

Barkhoudarian $\mathrm{G}$ is a consultant for Vascular Technologies Inc.

\section{Ethical approval and consent to participate}

Not applicable.

\section{Consent for publication}

Not applicable. 


\section{Copyright}

(c) The Authors 2021.

\section{REFERENCES}

1. Elhadi AM, Hardesty DA, Zaidi HA, et al. Evaluation of surgical freedom for microscopic and endoscopic transsphenoidal approaches to the sella. Neurosurgery 2015;11 Suppl 2:69-78; discussion 78. DOI PubMed

2. Lobo B, Heng A, Barkhoudarian G, Griffiths CF, Kelly DF. The expanding role of the endonasal endoscopic approach in pituitary and skull base surgery: A 2014 perspective. Surg Neurol Int 2015;6:82. DOI PubMed PMC

3. McLaughlin N, Eisenberg AA, Cohan P, Chaloner CB, Kelly DF. Value of endoscopy for maximizing tumor removal in endonasal transsphenoidal pituitary adenoma surgery. J Neurosurg 2013;118:613-20. DOI PubMed

4. Louis RG, Eisenberg A, Barkhoudarian G, Griffiths C, Kelly DF. Evolution of minimally invasive approaches to the sella and parasellar region. Int Arch Otorhinolaryngol 2014;18:S136-48. DOI PubMed PMC

5. Cavallo LM, Somma T, Solari D, et al. Endoscopic Endonasal Transsphenoidal Surgery: History and Evolution. World Neurosurg 2019;127:686-94. DOI PubMed

6. Wang EW, Zanation AM, Gardner PA, et al. ICAR: endoscopic skull-base surgery. Int Forum Allergy Rhinol 2019;9:S145-365. DOI PubMed

7. Dehdashti AR, Ganna A, Witterick I, Gentili F. Expanded endoscopic endonasal approach for anterior cranial base and suprasellar lesions: indications and limitations. Neurosurgery 2009;64:677-87; discussion 687. DOI PubMed

8. Kassam A, Snyderman CH, Mintz A, Gardner P, Carrau RL. Expanded endonasal approach: the rostrocaudal axis. Part I. Crista galli to the sella turcica. Neurosurg Focus 2005;19:E3. PubMed

9. Mahmoud M, Nader R, Al-Mefty O. Optic canal involvement in tuberculum sellae meningiomas: influence on approach, recurrence, and visual recovery. Neurosurgery 2010;67:ons108-18; discussion ons118. DOI PubMed

10. Ansari SF, Eisenberg A, Rodriguez A, Barkhoudarian G, Kelly DF. The supraorbital eyebrow craniotomy for intra- and extra-axial brain tumors: a single-center series and technique modification. Oper Neurosurg (Hagerstown) 2020:opaa217. DOI PubMed

11. Fatemi N, Dusick JR, de Paiva Neto MA, Malkasian D, Kelly DF. Endonasal versus supraorbital keyhole removal of craniopharyngiomas and tuberculum sellae meningiomas. Neurosurgery 2009;64:269-84; discussion 284. DOI PubMed

12. Divitiis E. Endoscopic endonasal transsphenoidal surgery: from the pituitary fossa to the midline cranial base. World Neurosurg 2013;80:e45-51. DOI PubMed

13. Koutourousiou M, Fernandez-Miranda JC, Stefko ST, Wang EW, Snyderman CH, Gardner PA. Endoscopic endonasal surgery for suprasellar meningiomas: experience with 75 patients. J Neurosurg 2014;120:1326-39. DOI PubMed

14. Ditzel Filho LF, Prevedello DM, Jamshidi AO, et al. Endoscopic endonasal approach for removal of tuberculum sellae meningiomas. Neurosurg Clin N Am 2015;26:349-61. DOI PubMed

15. Sakata K, Takeshige N, Nagata Y, et al. Endoscopic endonasal removal of primary/recurrent meningiomas in the medial optic canal: surgical technique and long-term visual outcome. Oper Neurosurg (Hagerstown) 2019;17:470-80. DOI PubMed

16. Di Somma A, Torales J, Cavallo LM, et al. Defining the lateral limits of the endoscopic endonasal transtuberculum transplanum approach: anatomical study with pertinent quantitative analysis. J Neurosurg 2018;130:848-60. DOI PubMed

17. Abhinav K, Acosta Y, Wang WH, et al. Endoscopic Endonasal approach to the optic canal: anatomic considerations and surgical relevance. Neurosurgery 2015;11 Suppl 3:431-45; discussion 445. DOI PubMed

18. Shetty SR, Ruiz-Treviño AS, Omay SB, et al. Limitations of the endonasal endoscopic approach in treating olfactory groove meningiomas. A systematic review. Acta Neurochir (Wien) 2017;159:1875-85. DOI PubMed

19. Yang C, Fan Y, Shen Z, Wang R, Bao X. Transsphenoidal versus transcranial approach for treatment of tuberculum sellae meningiomas: a systematic review and meta-analysis of comparative studies. Sci Rep 2019;9:4882. DOI PubMed PMC

20. Soni RS, Patel SK, Husain Q, Dahodwala MQ, Eloy JA, Liu JK. From above or below: the controversy and historical evolution of tuberculum sellae meningioma resection from open to endoscopic skull base approaches. J Clin Neurosci 2014;21:559-68. DOI PubMed

21. Komotar RJ, Starke RM, Raper DM, Anand VK, Schwartz TH. Endoscopic endonasal versus open transcranial resection of anterior midline skull base meningiomas. World Neurosurg 2012;77:713-24. DOI PubMed

22. Magill ST, Morshed RA, Lucas CG, et al. Tuberculum sellae meningiomas: grading scale to assess surgical outcomes using the transcranial versus transsphenoidal approach. Neurosurg Focus 2018;44:E9. DOI PubMed

23. Divitiis E, Esposito F, Cappabianca P, Cavallo LM, de Divitiis O. Tuberculum sellae meningiomas: high route or low route? Neurosurgery 2008;62:556-63; discussion 556. DOI PubMed

24. Kong DS, Hong CK, Hong SD, et al. Selection of endoscopic or transcranial surgery for tuberculum sellae meningiomas according to specific anatomical features: a retrospective multicenter analysis (KOSEN-002). J Neurosurg 2018;130:838-47. DOI PubMed

25. Makarenko S, Carreras EM, Akagami R. Craniotomy for perisellar meningiomas: comparison of simple (appropriate for endoscopic approach) versus complex anatomy and surgical outcomes. J Neurosurg 2017;126:1191-200. DOI PubMed

26. Bander ED, Singh H, Ogilvie CB, et al. Endoscopic endonasal versus transcranial approach to tuberculum sellae and planum sphenoidale meningiomas in a similar cohort of patients. J Neurosurg 2018;128:40-8. DOI PubMed

27. Karsy M, Raheja A, Eli I, Guan J, Couldwell WT. Clinical outcomes with transcranial resection of the tuberculum sellae meningioma. World Neurosurg 2017;108:748-55. DOI PubMed

28. Wilson DA, Duong H, Teo C, Kelly DF. The supraorbital endoscopic approach for tumors. World Neurosurg 2014;82:e243-56. DOI 
PubMed

29. Kelly DF, Griffiths CF, Takasumi Y, Rhee J, Barkhoudarian G, Krauss HR. Role of endoscopic skull base and keyhole surgery for pituitary and parasellar tumors impacting vision. J Neuroophthalmol 2015;35:335-41. DOI PubMed

30. Mallari RJ, Thakur JD, Rhee J, et al. Endoscopic endonasal and supraorbital removal of tuberculum sellae meningiomas: anatomical guides and operative nuances for keyhole approach selection. Oper Neurosurg. Forthcoming 2021.

31. Conger A, Zhao F, Wang X, et al. Evolution of the graded repair of CSF leaks and skull base defects in endonasal endoscopic tumor surgery: trends in repair failure and meningitis rates in 509 patients. J Neurosurg 2018;130:861-75. DOI PubMed

32. Gupta A, Stierer T, Zuckerman R, Sakima N, Parker SD, Fleisher LA. Comparison of recovery profile after ambulatory anesthesia with propofol, isoflurane, sevoflurane and desflurane: a systematic review. Anesth Analg 2004;98:632-41, table of contents. DOI PubMed

33. Gutierrez WR, Bennion DM, Walsh JE, Owen SR. Vascular pedicled flaps for skull base defect reconstruction. Laryngoscope Investig Otolaryngol 2020;5:1029-38. DOI PubMed PMC

34. Zanation AM, Snyderman CH, Carrau RL, Kassam AB, Gardner PA, Prevedello DM. Minimally invasive endoscopic pericranial flap: a new method for endonasal skull base reconstruction. Laryngoscope 2009;119:13-8. DOI PubMed

35. Hannan CJ, Kelleher E, Javadpour M. Methods of Skull Base Repair Following Endoscopic Endonasal Tumor Resection: A Review. Front Oncol 2020;10:1614. DOI PubMed PMC

36. Ottenhausen M, Banu MA, Placantonakis DG, et al. Endoscopic endonasal resection of suprasellar meningiomas: the importance of case selection and experience in determining extent of resection, visual improvement, and complications. World Neurosurg 2014;82:442-9. DOI PubMed

37. Song SW, Kim YH, Kim JW, et al. Outcomes After Transcranial and Endoscopic Endonasal Approach for Tuberculum MeningiomasA Retrospective Comparison. World Neurosurg 2018;109:e434-45. DOI PubMed

38. Elshazly K, Kshettry VR, Farrell CJ, Nyquist G, Rosen M, Evans JJ. Clinical outcome after endoscopic endonasal resection of tuberculum sella meningiomas. Oper Neurosurg (Hagerstown) 2018;14:494-502. DOI PubMed

39. Zoli M, Guaraldi F, Pasquini E, Frank G, Mazzatenta D. The endoscopic endonasal management of anterior skull base meningiomas. $J$ Neurol Surg B Skull Base 2018;79:S300-10. DOI PubMed PMC

40. Salek MAA, Faisal MH, Manik MAH, Choudhury AU, Chowdhury RU, Islam MA. Endoscopic endonasal transsphenoidal approach for resection of tuberculum sella and planum sphenoidale meningiomas: a snapshot of our institutional experience. Asian J Neurosurg 2020;15:22-5. DOI PubMed PMC

41. Linsler S, Fischer G, Skliarenko V, Stadie A, Oertel J. Endoscopic assisted supraorbital keyhole approach or endoscopic endonasal approach in cases of tuberculum sellae meningioma: which surgical route should be favored? World Neurosurg 2017;104:601-11. DOI PubMed

42. Khan $\mathrm{OH}$, Krischek B, Holliman D, et al. Pure endoscopic expanded endonasal approach for olfactory groove and tuberculum sellae meningiomas. J Clin Neurosci 2014;21:927-33. DOI PubMed

43. Hayhurst C, Sughrue ME, Gore PA, Bonney PA, Burks JD, Teo C. Results with expanded endonasal resection of skull base meningiomas technical nuances and approach selection based on an early experience. Turk Neurosurg 2016;26:662-70. DOI PubMed

44. Zamanipoor Najafabadi AH, Khan DZ, Muskens IS, et al. Trends in cerebrospinal fluid leak rates following the extended endoscopic endonasal approach for anterior skull base meningioma: a meta-analysis over the last 20 years. Acta Neurochir (Wien) 2021;163:711-9. DOI PubMed PMC

45. Youngerman BE, Banu MA, Gerges MM, et al. Endoscopic endonasal approach for suprasellar meningiomas: introduction of a new scoring system to predict extent of resection and assist in case selection with long-term outcome data. J Neurosurg 2020:1-13. DOI PubMed

46. Kitano M, Taneda M, Nakao Y. Postoperative improvement in visual function in patients with tuberculum sellae meningiomas: results of the extended transsphenoidal and transcranial approaches. J Neurosurg 2007;107:337-46. DOI PubMed

47. Wang Q, Lu XJ, Ji WY, et al. Visual outcome after extended endoscopic endonasal transsphenoidal surgery for tuberculum sellae meningiomas. World Neurosurg 2010;73:694-700. DOI PubMed

48. Gompel JJ, Frank G, Pasquini E, Zoli M, Hoover J, Lanzino G. Expanded endonasal endoscopic resection of anterior fossa meningiomas: report of 13 cases and meta-analysis of the literature. Neurosurg Focus 2011;30:E15. DOI PubMed

49. Ogawa Y, Tominaga T. Extended transsphenoidal approach for tuberculum sellae meningioma--what are the optimum and critical indications? Acta Neurochir (Wien) 2012;154:621-6. DOI PubMed

50. Ceylan S, Anik I, Koc K, Cabuk B. Extended endoscopic transsphenoidal approach infrachiasmatic corridor. Neurosurg Rev 2015;38:137-47; discussion 147. DOI PubMed

51. Bernat AL, Priola SM, Elsawy A, et al. Recurrence of anterior skull base meningiomas after endoscopic endonasal resection: 10 years' experience in a series of 52 endoscopic and transcranial cases. World Neurosurg 2018;120:e107-13. DOI PubMed

52. Griffiths CF, Cutler AR, Duong HT, et al. Avoidance of postoperative epistaxis and anosmia in endonasal endoscopic skull base surgery: a technical note. Acta Neurochir (Wien) 2014;156:1393-401. DOI PubMed

53. Purohit A, Jha R, Khalafallah AM, Price C, Rowan NR, Mukherjee D. Endoscopic endonasal versus transcranial approach to resection of olfactory groove meningiomas: a systematic review. Neurosurg Rev 2020;43:1465-71. DOI PubMed

54. Shin M, Kondo K, Saito N. Current status of endoscopic endonasal surgery for skull base meningiomas: review of the literature. Neurol Med Chir (Tokyo) 2015;55:735-43. DOI PubMed PMC

55. Banu MA, Mehta A, Ottenhausen M, et al. Endoscope-assisted endonasal versus supraorbital keyhole resection of olfactory groove meningiomas: comparison and combination of 2 minimally invasive approaches. J Neurosurg 2016;124:605-20. DOI PubMed 
56. de Almeida JR, Carvalho F, Vaz Guimaraes Filho F, et al. Comparison of endoscopic endonasal and bifrontal craniotomy approaches for olfactory groove meningiomas: A matched pair analysis of outcomes and frontal lobe changes on MRI. J Clin Neurosci 2015;22:1733-41. DOI PubMed

57. Koutourousiou M, Fernandez-Miranda JC, Wang EW, Snyderman CH, Gardner PA. Endoscopic endonasal surgery for olfactory groove meningiomas: outcomes and limitations in 50 patients. Neurosurg Focus 2014;37:E8. DOI PubMed

58. Graffeo CS, Dietrich AR, Grobelny B, et al. A panoramic view of the skull base: systematic review of open and endoscopic endonasal approaches to four tumors. Pituitary 2014;17:349-56. DOI PubMed PMC

59. Padhye V, Naidoo Y, Alexander H, et al. Endoscopic endonasal resection of anterior skull base meningiomas. Otolaryngol Head Neck Surg 2012;147:575-82. DOI PubMed

60. Zhang Q, Wang Z, Guo H, et al. Resection of anterior cranial base meningiomas with intra- and extracranial involvement via a purely endoscopic endonasal approach. ORL J Otorhinolaryngol Relat Spec 2012;74:199-207. DOI PubMed

61. Divitiis E, Esposito F, Cappabianca P, Cavallo LM, de Divitiis O, Esposito I. Endoscopic transnasal resection of anterior cranial fossa meningiomas. Neurosurg Focus 2008;25:E8. DOI PubMed

62. Liu JK, Silva NA, Sevak IA, Eloy JA. Transbasal versus endoscopic endonasal versus combined approaches for olfactory groove meningiomas: importance of approach selection. Neurosurg Focus 2018;44:E8. DOI PubMed

63. Jang WY, Jung S, Jung TY, Moon KS, Kim IY. Preservation of olfaction in surgery of olfactory groove meningiomas. Clin Neurol Neurosurg 2013;115:1288-92. DOI PubMed

64. Youssef AS, Sampath R, Freeman JL, Mattingly JK, Ramakrishnan VR. Unilateral endonasal transcribriform approach with septal transposition for olfactory groove meningioma: can olfaction be preserved? Acta Neurochir (Wien) 2016;158:1965-72. DOI PubMed 